\title{
A realidade das informações da política de medicamentos especializados nos websites das Secretarias Estaduais de Saúde
}

\author{
The reality of the information of the specialized drug policy on the \\ websites of the State Health Departments
}

\section{La realidad de la información especializada sobre políticas de medicamentos en los sitios web del Departamento de Salud del Estado}

Tatiana Sanjuan Ganem Waetge

tatiana.sanjuan@bio.fiocruz.br | https://orcid.org/o0oo-0002-1149-6991

Carlos José Saldanha Machado

carlos.saldanha@fiocruz.br | http://orcid.org/oooo-0001-7642-1379

\footnotetext{
${ }^{1}$ Fundação Oswaldo Cruz, Instituto de Tecnologia em Imunobiológicos. Rio de Janeiro, RJ, Brasil.

2 Fundação Oswaldo Cruz, Instituto de Comunicação e Informação Científica e Tecnológica em Saúde, Laboratório de Informação Científica e Tecnológica em Saúde. Rio de Janeiro, RJ, Brasil.

a Doutorado em Informação e Comunicação em Saúde pela Fundação Oswaldo Cruz.

${ }^{\mathrm{b}}$ Doutorado em Antropologia pela Université Paris Descartes.
}

\section{RESUMO}

O objetivo desse artigo é analisar como os sites das Secretarias Estaduais de Saúde da Paraíba, Bahia, Santa Catarina e Rio Grande do Sul disponibilizam informações sobre a política de medicamentos brasileira para os usuários do SUS. Com base em uma metodologia qualitativa, observa-se uma variedade de formas de organização e apresentação das informações estruturadas em uma linguagem predominantemente técnica, em desacordo com o nível de instrução da população, em oposição à uma comunicação pública que deve ser, segundo a norma legal, acessível e compreensível por gestores, profissionais e atores da sociedade civil, superando o linguajar do corpo técnico-burocrático para que a política pública seja apropriada pela sociedade. Ao identificar uma distância existente entre lei e realidade, conclui-se enunciando limites e desafios a serem superados pelos agentes políticos no aprofundamento e desenvolvimento de metodologias voltadas para a qualidade do acesso às informações da política pública de medicamentos pela população.

Palavras-chave: Assistência Farmacêutica; Acesso a medicamentos; Informação em saúde; Governo eletrônico ou e-Gov; Democratização da informação. 


\section{ABSTRACT}

The objective of this article is to analyze how the websites of the State Health Departments of Paraíba, Bahia, Santa Catarina and Rio Grande do Sul provide information about the Brazilian drug policy for SUS users. Based on a qualitative methodology, a variety of forms of organization and presentation of structured information are observed in a predominantly technical language, in disagreement with the level of education of the population of these states, as opposed to a public communication that must be, according to the legal norm, accessible and understandable by managers, professionals and civil society actors, overcoming the language of the technical-bureaucratic body so that public policy is appropriated by society. When identifying a distance between law and reality, it concludes by stating a limits and challenges to be overcome by the political agents in the deepening and development of methodologies focused on the quality of access to information on public policy of medicines by the population.

Keywords: Pharmaceutical Assistance; Access to medicines; Health information; E-government or e-Gov; Democratization of information.

\section{RESUMEN}

El propósito de este documento es analizar cómo los sitios web de los Departamentos de Salud del Estado de Paraíba, Bahía, Santa Catarina y Rio Grande do Sul proporcionan información sobre la política de drogas de Brasil a los usuarios del SUS. Basado en una metodología cualitativa, se puede observar una variedad de formas de organización y presentación de información estructurada en un lenguaje predominantemente técnico, en desacuerdo con el nivel educativo de la población, en oposición a una comunicación pública que debe ser, según la norma, legal, accesible y comprensible para gerentes, profesionales y actores de la sociedad civil, superando el lenguaje del cuerpo técnico-burocrático para que la sociedad se apropie de las políticas públicas. Al identificar una distancia existente entre la ley y la realidad, concluimos estableciendo límites y desafíos que deben superar los agentes políticos en la profundización y el desarrollo de metodologías dirigidas a la calidad del acceso a la información de las políticas públicas sobre medicamentos por parte de la población.

Palabras clave: Asistencia farmacéutica; Acceso a medicamentos; Información de salud; Gobierno electrónico; Democratización de la información.

Contribuição dos autores:

Concepção e desenho do estudo: Tatiana Sanjuan.

Aquisição, análise ou interpretação dos dados: Tatiana Sanjuan.

Redação do manuscrito: Tatiana Sanjuan e Carlos Saldanha.

Revisão crítica do conteúdo intelectual: Tatiana Sanjuan e Carlos Saldanha.

Declaração de conflito de interesses: não há.

Fontes de financiamento: não houve.

Considerações éticas: não há.

Agradecimentos/Contribuições adicionais: não há.

Histórico do artigo: submetido: 11 nov 2019 | aceito: 5 ago. 2020 | publicado: 17 dez. 2020.

Apresentação anterior: não houve.

Licença CC BY-NC atribuição não comercial. Com essa licença é permitido acessar, baixar (download), copiar, imprimir, compartilhar, reutilizar e distribuir os artigos, desde que para uso não comercial e com a citação da fonte, conferindo os devidos créditos de autoria e menção à Reciis. Nesses casos, nenhuma permissão é necessária por parte dos autores ou dos editores. 


\section{INTRODUÇÃO}

A política pública de medicamentos objetiva o tratamento e outras indicações médicas, distribuindo medicação utilizada pela sociedade por meio das farmácias e unidades prestadoras de serviços de saúde ${ }^{1}$. Os serviços de saúde de acesso a medicamentos no Brasil operam por meio da assistência farmacêutica (AF), organizada em componentes (blocos) com variações importantes em termos de financiamento, aquisição e gestão pelas três esferas de governo (federal, estadual e municipal) e fluxos variados. O Componente Especializado da Assistência Farmacêutica (CEAF) contempla o tratamento medicamentoso de setenta e nove doenças, geralmente, graves, crônicas e de alta especialização ${ }^{2}$. Por conta dessas características, o acesso aos medicamentos pela população se dá de forma mais complexa que os demais componentes (Básico e Estratégico) demandando um maior controle do sistema para a segurança do paciente. Esse procedimento passa pelo cumprimento das normas estabelecidas pela Portaria $\mathrm{n}^{0}$ 02, de 28 de setembro de 2017, de Consolidação das Normas sobre as Políticas Nacionais de Saúde do SUS ${ }^{3}$, compreendidas em etapas de execução: solicitação, avaliação, autorização, dispensação e renovação da continuidade do tratamento. De forma geral, toda solicitação de medicamentos do componente especializado deve passar por uma avaliação do cumprimento de critérios documentais e biomédicos, conforme disposto nos Protocolos Clínicos e Diretrizes Terapêuticas (PCDT) específicos de cada doença. Essas características administrativas do CEAF demandam dos profissionais envolvidos - gestores e profissionais de saúde, especialmente médicos e farmacêuticos - e dos pacientes conhecimentos sobre os fluxos de acesso ao Componente para que estes não se configurem em barreiras de acesso à política de medicamentos por meio dos serviços de saúde.

O objetivo desse artigo é contribuir para o aprimoramento da política pública de medicamentos por meio da análise de um de seus instrumentos de ação: página eletrônica (websites) para o acesso às informações da política nacional dos medicamentos especializados das Secretarias Estaduais de Saúde (SES). O cumprimento dos direitos sociais, especialmente no campo da saúde, depende da adequada e efetiva implementação das políticas públicas, sobretudo, no Sistema Único de Saúde (SUS), um conjunto de órgãos administrativos integrados cuja função é a promoção das atividades públicas de proteção à saúde, em todas as unidades da federação. Portanto, o direito a uma política pública de saúde eficiente e adequada é condição de possibilidade para a efetivação dos direitos dos cidadãos. Ademais, a presença de barreiras na efetividade das políticas públicas contribui para a estagnação ou piora da situação de saúde da população que necessita de tal cobertura.

Desse modo, partimos do entendimento de que, em um estado democrático de direito de um país com dimensão continental como o Brasil, marcado por diferenças regionais e socioeconômicas (desníveis nos indicadores de mortalidade e morbidade entre diferentes grupos populacionais dentro de uma mesma região, estado ou cidade, expressão das desigualdades em termos de renda, moradia, saneamento, educação e acesso aos serviços de saúde), a efetivação das políticas públicas passa pela capacidade que têm as tecnologias de informação e comunicação de orientar o cidadão e promover o acesso aos serviços públicos. Como observa Gadelha4,"“a humanização do cuidado e a inovação tecnológica e social podem ocorrer em um novo e mesmo processo, gerando acolhimento, cidadania, emprego, renda, investimento e conhecimento estratégico para o futuro". Nesse sentido, a análise de uma política pública por meio de seus instrumentos é uma maneira de observar, segundo Lascoumes e Le Gales 5 , "as relações entre a sociedade política (via executivo-administrativo) e a sociedade civil (via sujeitos administrados) por intermediários, dispositivos misturando componentes técnicos (medida, cálculo, regra de direito, procedimento) e sociais (representação, símbolo) [...] e obrigações, relações financeiras e meios de conhecimento das populações".

Por sua vez, a escolha de um dos elementos que estruturam a política de medicamentos, o acesso digital e on-line às informações de medicamentos especializados pelos cidadãos, deve-se ao fato de $69,9 \%$ da populção brasileira terem acesso à Internet ${ }^{6}$, mesmo com uma parcela expressiva sendo considerada 
"funcionalmente alfabetizados". Enquadram-se nessa categoria sete entre 10 brasileiros na faxa etária de $15 \mathrm{e}$ 64 anos, sendo 34\% dessa parcela de nível rudimentar de leitura e interpretação textual. Os demais níveis da categoria funcionalmente alfabetizados são intermediário (25\%) e proficiente (12\%)․ Nacionalmente, a maior proporção de analfabetos se concentra nos municípios das regiões Nordeste e Norte - além do norte do estado de Minas Gerais - duas regiões que concentram os municípios com maior desigualdade de renda domiciliar per capita, medida pelo índice de Gini ${ }^{8}$.

Face a essa realidade, cabe perguntar que tipo de comunicação é praticada pelas Secretarias Estaduais de Saúde em seus sites. Pratica-se uma comunicação acessível e compreensível a todos os interessados, de forma a criar condições para que o usuário do SUS possa exercer sua cidadania de forma autônoma, apropriando-se da política pública de medicamentos a que tem direito? Quais são as características, limites e desafios do instrumento de política pública em análise? Ainda que não haja estudos demonstrando a correlação entre volume e qualidade das informações sobre medicamentos e apropriação da política pública pela população, defendemos que essa democratização é fundamental para o desenvolvimento de uma cultura crítica em relação a medicamentos no Brasil estruturalmente desigual e iníquo. A despeito de toda desigualdade existente e mesmo nas condições adversas do país, investir na demonstração dessa hipótese é mais adequado politicamente do que deixar de defender uma administração pública democrática. Nosso posicionamento teórico caminha na defesa do amplo acesso à informação das políticas públicas incorporadas no sistema público de saúde, sobretudo, por conta da existência de problemas estruturais na organização do estado brasileiro. Finalmente, dada a relevância do tema para a Saúde Coletiva, é importante conhecer as potencialidades e limitações registradas pelas SES em suas páginas eletrônicas para o acesso aos medicamentos especializados e analisar questões fundamentais relacionadas à implementação de políticas públicas em estados situados em regiões distintas para avançar em metodologias voltadas para o aprimoramento da compreensão efetiva, pelo usuário do SUS, do componente dos conhecimentos que constituem a política de medicamentos.

Nas seções a seguir serão descritos os métodos empregados no estudo, apresentados os dados levantados, e discutidas as análises dos sites das SES selecionadas, concluindo com a enunciação de alguns limites a serem superados e desafios a serem enfrentados pelo poder público estadual para que a implementação da política nacional de medicamentos especializados seja adequada à realidade socioeducacional de cada estado.

\section{MÉTODOS}

Trata-se de um estudo qualitativo e descritivo sobre as páginas eletrônicas das SES de dois estados representantes das regiões Nordeste e Sul do país, porque expressam as desigualdades sociais mais proeminentes quando se leva em consideração indicadores da Síntese de Indicadores Sociais - SIS $^{9}$ a partir de três recortes primordiais: Mercado de trabalho, Padrão de vida e Distribuição de renda, e Educação, que visam a contemplar a heterogeneidade da sociedade brasileira sob a perspectiva das desigualdades sociais. Esses indicadores expressam "a qualidade de vida e os níveis de bem-estar das pessoas, famílias e grupos populacionais, a efetivação de direitos humanos e sociais, bem como o acesso a diferentes serviços, bens e oportunidades". Os indicadores selecionados foram: Taxa de analfabetismo, Rendimento real efetivo domiciliar per capita, Taxa de desocupação e índice Gini. Desse modo, foram selecionadas os estados da Bahia, Paraíba, Santa Catarina e Rio Grande do Sul, situados em regiões com os piores e com os melhores resultados expressos na tabela 1. 
Tabela 1 - Dados Socioeconômicos

\begin{tabular}{|c|c|c|c|c|}
\hline Região & Educação & Rendimento & Trabalho & $\begin{array}{l}\text { Desigualdade } \\
\text { de renda }\end{array}$ \\
\hline & $\begin{array}{l}\text { Taxa de analfabetismo } \\
\text { da população de } 15 \\
\text { anos ou mais de idade }\end{array}$ & $\begin{array}{l}\text { Rendimento real efetivo } \\
\text { domiciliar per capita } \\
\text { médio e mediano das } \\
\text { pessoas residentes em } \\
\text { domicílios particulares }\end{array}$ & $\begin{array}{l}\text { Taxa de desocupação } \\
\text { das pessoas de } 14 \\
\text { anos ou mais de } \\
\text { idade }\end{array}$ & $\begin{array}{l}\text { Índice de Gini da } \\
\text { distribuição do } \\
\text { rendimento real } \\
\text { efetivo domiciliar } \\
\text { per capita }\end{array}$ \\
\hline Brasil & 7 & 1285 & 12,5 & 0,549 \\
\hline Norte & 8 & 829 & 11,9 & 0,544 \\
\hline Nordeste & 14,5 & 815 & 14,7 & 0,567 \\
\hline Sudeste & 3,5 & 1547 & 13,3 & 0,529 \\
\hline Sul & 3,5 & 1566 & 8,3 & 0,477 \\
\hline Centro-Oeste & 5,2 & 1533 & 10,5 & 0,536 \\
\hline
\end{tabular}

Fonte: IBGE (2018).

Para a seleção dos quatro estados foi também levada em consideração a correlação de indicadores oficiais do acesso a medicamentos especializados e o percentual de acesso à internet por estado, conforme a tabela 2. Os estados selecionados são aqueles situados entre a menor e a maior relação entre as seguintes variáveis: a) valor financeiro aprovado pelo MS para os medicamentos do CEAF (produção de APAC Autorização de Procedimentos de Alta Complexidade) baseado no DATASUS, 2018-2019, b) tamanho da população residente por estado e c) percentual de acesso à internet pela população de cada estado baseados na PNAD/IBGE, 2017.

Tabela 2 - Critério de seleção dos estados e nível de instrução da população

\begin{tabular}{|c|c|c|c|c|}
\hline $\begin{array}{l}\text { Região/ } \\
\text { Estados }\end{array}$ & $\begin{array}{l}\text { População } \\
\text { Residente } \times 10^{3} \text { (a) }\end{array}$ & $\begin{array}{l}\text { Valor (R\$) } \\
\text { aprovado CEAF } \\
\text { x10 } \\
\text { (b) }\end{array}$ & $\begin{array}{l}\text { Gasto médio mensal/ } \\
\text { mil hab. (R\$) }\end{array}$ & $\begin{array}{l}\text { Acesso internet } \\
(\%)^{(c)}\end{array}$ \\
\hline Norte & 18.182 & 1.366 & 62,7 & 60,1 \\
\hline Rondônia & 1.758 & 119 & 67,7 & 66,4 \\
\hline Acre & 869 & 31 & 35,5 & 57,1 \\
\hline Amazonas & 4.081 & 391 & 95,7 & 59,6 \\
\hline Roraima & 577 & 11 & 18,7 & 71,6 \\
\hline Pará & 8.513 & 606 & 71,2 & 57,3 \\
\hline Amapá & 829 & 28 & 33,9 & 70,2 \\
\hline Tocantins & 1.555 & 180 & 116,0 & 61,8 \\
\hline Nordeste & 56.761 & 6.195 & 123,9 & 58,4 \\
\hline Maranhão & 7.035 & 581 & 82,5 & 48,1 \\
\hline Piauí & 3.265 & 362 & 110,9 & 54,2 \\
\hline Ceará & 9.076 & 1.410 & 155,4 & 59,4 \\
\hline Rio Grande do Norte & 3.479 & 227 & 65,3 & 65,5 \\
\hline Paraíba & 3.996 & 1.027 & 257,0 & 59,7 \\
\hline Pernambuco & 9.496 & 876 & 92,3 & 59,8 \\
\hline Alagoas & 3.323 & 424 & 127,5 & 52,7 \\
\hline Sergipe & 2.278 & 369 & 162,0 & 64,6 \\
\hline Bahia & 14.813 & 919 & 62,0 & 60,7 \\
\hline Sudeste & 87.712 & 30.499 & 295,9 & 76,5 \\
\hline
\end{tabular}




\begin{tabular}{|c|c|c|c|c|}
\hline $\begin{array}{l}\text { Região/ } \\
\text { Estados }\end{array}$ & $\begin{array}{l}\text { População } \\
\text { Residente } \times 10^{3} \text { (a) }\end{array}$ & $\begin{array}{l}\text { Valor }(\mathrm{R} \$) \\
\text { aprovado CEAF } \\
\times 10^{3} \text { (b) }\end{array}$ & $\begin{array}{l}\text { Gasto médio mensal/ } \\
\text { mil hab. }(\mathbf{R} \$)\end{array}$ & $\begin{array}{l}\text { Acesso internet } \\
(\%)^{(\mathrm{c})}\end{array}$ \\
\hline Minas Gerais & 21.041 & 4.403 & 209,3 & 69,8 \\
\hline Espírito Santo & 3.972 & 1.500 & 377,6 & 71,6 \\
\hline Rio de Janeiro & 17.160 & 1.556 & 90,7 & 77,8 \\
\hline São Paulo & 45.539 & 23.040 & 505,9 & 79,6 \\
\hline Região Sul & 29.754 & 8.625 & 300,3 & 73,2 \\
\hline Paraná & 11.349 & 4.365 & 384,6 & 72,8 \\
\hline Santa Catarina & 7.075 & 2.644 & 373,7 & 76,3 \\
\hline Rio Grande do Sul & 11.330 & 1.615 & 142,6 & 71,7 \\
\hline Centro Oeste & 16.086 & 4.306 & 275,4 & 76,6 \\
\hline Mato Grosso do Sul & 2.748 & 1.040 & 378,6 & 74,8 \\
\hline Mato Grosso & 3.442 & 636 & 184,7 & 72,8 \\
\hline Goiás & 6.921 & 1.804 & 260,7 & 75,3 \\
\hline Distrito Federal & 2.975 & 826 & 277,5 & 85,3 \\
\hline
\end{tabular}

Fontes: a. IBGE (2018) ${ }^{9}$ b. DATASUS (2019) c. PNADC Internet/IBGE (2017).

Os dados oficiais do perfil socioeconômico e educacional da população brasileira (IBGE) foram utilizados para compor a análise com os achados na avaliação das páginas eletrônicas. Dessa forma, foi possível estabelecer comparações entre as informações disponibilizadas nos websites das SES e o perfil populacional do Brasil e dos estados analisados (tabela 3).

Tabela 3 - Nível de instrução das pessoas de 25 anos ou mais de idade

\begin{tabular}{llllllll}
$\begin{array}{l}\text { Região/ } \\
\text { Estados }\end{array}$ & $\begin{array}{l}\text { Sem } \\
\text { instrução }\end{array}$ & $\begin{array}{l}\text { Fundamental } \\
\text { incompleto }\end{array}$ & $\begin{array}{l}\text { Ensino } \\
\text { Fundamental }\end{array}$ & $\begin{array}{l}\text { Médio } \\
\text { incompleto }\end{array}$ & $\begin{array}{l}\text { Ensino } \\
\text { Médio }\end{array}$ & $\begin{array}{l}\text { Superior } \\
\text { incompleto }\end{array}$ & $\begin{array}{l}\text { Ensino } \\
\text { Superior }\end{array}$ \\
Norte & 8,8 & 36,4 & 7,3 & 5,4 & 26,8 & 3,7 & 11,6 \\
Rondônia & 8,8 & 41,5 & 8 & 5,3 & 22,1 & 3,2 & 11,1 \\
Acre & 13,6 & 34,1 & 7,6 & 4,2 & 22,9 & 3,7 & 14 \\
Amazonas & 7,6 & 30,6 & 6,7 & 4,2 & 32,5 & 4,6 & 13,9 \\
Roraima & 7,9 & 25,3 & 5,7 & 5,7 & 31,9 & 5,5 & 18,1 \\
Pará & 8,3 & 39,9 & 7,7 & 6,3 & 25,6 & 3 & 9,1 \\
Amapá & 6 & 27 & 7,3 & 6 & 29,4 & 6,4 & 17,9 \\
Tocantins & 13,5 & 33,9 & 5,8 & 4,5 & 24,7 & 3,6 & 13,9 \\
Nordeste & 14,3 & 37,3 & 6,6 & 4,5 & 24,2 & 2,7 & 10,3 \\
Maranhão & 17,8 & 36,3 & 7,5 & 4,6 & 24,2 & 2,1 & 7,4 \\
Piauí & 13,6 & 41 & 7,6 & 4,5 & 19,9 & 2,2 & 11,3 \\
Ceará & 14,5 & 35,6 & 8,5 & 4,4 & 24 & 3,1 & 10 \\
Rio G. do Norte & 9,3 & 39,9 & 6 & 5,3 & 24,7 & 3 & 11,8 \\
Paraíba & 13,8 & 39,6 & 6,2 & 4,2 & 20,4 & 3,1 & 12,7 \\
Pernambuco & 13 & 35,9 & 6,5 & 4,1 & 26 & 2,6 & 11,9 \\
Alagoas & 17,8 & 39,7 & 6,6 & 3,9 & 21,1 & 2,5 & 8,4 \\
Sergipe & 12,2 & 39,1 & 6,8 & 4,7 & 22,7 & 3,5 & 11 \\
\hline Bahia & 14,5 & 36,9 & 5,3 & 4,6 & 26 & 2,7 & 9,8 \\
\hline Sudeste & 3,8 & 30,4 & 9,3 & 4,2 & 29,6 & 3,8 & 18,8 \\
Minas Gerais & 4,9 & 40,5 & 9 & 4 & 24,5 & 3,4 & 13,7
\end{tabular}




\begin{tabular}{llllllll}
$\begin{array}{l}\text { Região/ } \\
\text { Estados }\end{array}$ & $\begin{array}{l}\text { Sem } \\
\text { instrução }\end{array}$ & $\begin{array}{l}\text { Fundamental } \\
\text { incompleto }\end{array}$ & $\begin{array}{l}\text { Ensino } \\
\text { Fundamental }\end{array}$ & $\begin{array}{l}\text { Médio } \\
\text { incompleto }\end{array}$ & $\begin{array}{l}\text { Ensino } \\
\text { Médio }\end{array}$ & $\begin{array}{l}\text { Superior } \\
\text { incompleto }\end{array}$ & $\begin{array}{l}\text { Ensino } \\
\text { Superior }\end{array}$ \\
\hline Espírito Santo & 6,4 & 34 & 9,5 & 4,1 & 27,2 & 3,2 & 15,6 \\
Rio de Janeiro & 4,1 & 27 & 10,5 & 4,2 & 31,8 & 4,1 & 18,3 \\
São Paulo & 3 & 26,9 & 9 & 4,3 & 31,2 & 4 & 21,7 \\
Região Sul & 3,9 & 36,4 & 10,3 & 4,4 & 24,1 & 4,4 & 16,5 \\
Paraná & 5,8 & 35,2 & 9,3 & 4,6 & 25 & 3,2 & 16,9 \\
Santa Catarina & 2,6 & 36,3 & 11,4 & 3,8 & 24,7 & 3,9 & 17,3 \\
Rio Grande do & 2,8 & 37,7 & 10,6 & 4,5 & 22,9 & 5,8 & 15,8 \\
Sul & & 32,7 & 7,8 & 5 & 24,6 & 4,3 & 18,8 \\
Centro Oeste & 6,8 & & & 5,4 & 22,7 & 4,6 & 16,5 \\
Mato Grosso & 5,5 & 37,4 & 8,4 & 5 & 23,3 & 3,9 & 14,8 \\
do Sul & & 35,6 & 7,3 & 5,7 & 24,7 & 4,1 & 15,2 \\
Mato Grosso & 9,4 & 34,8 & 8,3 & 5,1 & 27,2 & 5 & 33,2 \\
Goiás & 7,6 & 34,8 & 6,8 & 3,8 & &
\end{tabular}

Fonte: PNADC Educação/IBGE (2017) .

\section{Unidades de observação}

Os quatro estados (dois de cada região geográfica selecionada) e respectivos sites selecionados de acordo com os indicadores apresentados na tabela 1 e 2:

- Região Nordeste: Paraíba (www.saude.pb.gov.br) e Bahia (www.saude.ba.gov.br)

- Região Sul: Santa Catarina (www.saude.sc.gov.br) e Rio Grande_do Sul (www.saude.rs.gov.br)

Devido à inexistência de uma metodologia disponível na literatura científica para o estudo da problemática em análise, desenvolvemos um percurso a partir de vários referenciais, agrupados em dois roteiros. Essas ferramentas de leitura, respectivamente, de natureza abrangente e específica - o Roteiro A e o Roteiro B têm uma composição heterogênea que demanda esclarecimento sobre alguns dos seus itens constitutivos, já referidos nos próprios roteiros. O Roteiro A é composto por questões relacionadas i) à Lei de Acesso à Informação $\mathrm{n}^{0}$ 12.527, de 18 de novembro de 2011 (doravente LAI) ${ }^{10}$, que regula o acesso a informações no país, ii) à Política Nacional de Governo Eletrônico (doravante e-Gov) ${ }^{11}$ e iii) ao índice de legibilidade ${ }^{12}$. As variáveis independentes analisadas por categoria no instrumento A foram: e-Gov - navegabilidade, desenho/layout, legibilidade e maturidade do serviço; LAI - conteúdo.

Quando o objetivo é medir o nível de complexidade de um texto, um conceito importante é o de 'leiturabilidade', tradução literal do inglês para readability, ou também em português, o termo inteligibilidade $^{12}$. Na atualidade, o conceito de inteligibilidade pode ser utilizado como a qualidade da linguagem que é compreensível, ou medida de quanto confortável ou quão facilmente um texto pode ser lido $^{12,13}$. Para avaliação da inteligibilidade, nos utilizamos, portanto, de técnicas de leitura direta (pessoal humana) e automatizada (índices). A leitura humana consiste na avaliação direta observando a linguagem adotada (técnica ou leiga) e a clareza das informações. De forma complementar, nos utilizamos de medidas de inteligibilidade que se dão por meio de fórmulas que "se concentram em aspectos lingüísticos do texto, que são mais fáceis de quantificar, constituindo um método fácil e barato de aplicação para predizer as dificuldades de leitura do texto"13. Trata-se de modelo matemático que avalia a estrutura de um texto quanto às suas frases, parágrafos e quantidade de sílabas das palavras (tamanho) ${ }^{14}$. Para o cálculo do índice de legibilidade do texto (ILT) utilizamos a fórmula de Flesch-Kincaid (ILFK) por ser a mais conhecida, estudada e validada 
para o idioma português ${ }^{15}$ : ILT = 248,835 (valor padrão) $-(1,015$ [valor padrão] x ASL) - (84,6 [valor padrão] x ASW), sendo ASL o tamanho médio do número de palavras dividido pelo número de sentenças, e ASW, o número médio de sílabas por palavra. Para o cálculo do índice, utilizamos o site de separador de sílabas on-line (www.separarensilabas.com) na identificação e contagem dos elementos (sílabas, palavras e sentenças) e, em seguida, aplicamos a fórmula. O ILT indica, em uma escala de zero a 100, a dificuldade de compreensão de um documento e a correspondência do grau de escolaridade apropriado para aquela leitura, estimando os anos de estudo necessários para a adequada compreensão, que é mensurado com base na adaptação ao sistema escolar brasileiro ${ }^{15}$ :

- Muito fáceis - índice entre 75 e 100: textos adequados para leitores com nível de escolaridade até o quinto ano do ensino fundamental;

- Fáceis - índice entre 50 e 75: textos adequados a alunos com escolaridade até o nono ano do ensino fundamental;

- Difíceis - índice entre 25 e 50: textos adequados para alunos cursando o ensino médio ou universitário;

- Muitos difíceis - índice entre zero e 25: textos adequados apenas para áreas acadêmicas específicas.

A fim de obtermos uma medida da clareza e compreensão da linguagem adotada nas informações disponibilizadas pelas SES, selecionamos um texto sobre a política de medicamentos de cada site estudado para a aplicação do ILT.

A segunda ferramenta de leitura, de natureza específica, o Roteiro B, está baseada nas regras que permitem o acesso ao CEAF estabelecidas pela Portaria $\mathrm{n}^{\circ}$ 02, de 28 de setembro de 2017, anexo XXVIII - Título IV - Trata das regras de Financiamento e Execução do CEAF no âmbito do SUS3 . As variáveis independentes analisadas por categoria no instrumento B foram: etapas de execução do CEAF - geral, solicitação, avaliação, dispensação e renovação.

As análises feitas por meio dos instrumentos de verificação geral e específico (Roteiro A e B) se deram a partir da página inicial dos websites oficiais das SES e foi centrada nas seções que disponibilizassem informações e orientações para a política da AF, especificamente do CEAF. O registro e a coleta de dados se deram no período de fevereiro a maio de 2019. A avaliação dos diferentes elementos que compõem o roteiro de leitura observou a ausência (valor zero) ou presença (valor um) dos aspectos abrangidos. A análise dos sites foi realizada a partir da navegação direta realizada pelo usuário comum, i.e., todo e qualquer cidadão que tenha o direito constitucional de acesso às informações das políticas públicas, na ocorrência, a do CEAF. Para a consulta das páginas das quatro SES adotamos o procedimento de baixar todo o material por conta de eventuais alterações com supressão ou inclusão de conteúdo novo nessas páginas. Após várias consultas, observamos que não houve alterações nelas.

\section{RESULTADOS}

Com base nos Roteiros de leitura geral (A) e específico (B), os dados sobre as páginas eletrônicas das SES foram reunidos nos quadros 1, 2 e 3. Convém ressaltar que, por limitação de espaço, os textos das páginas eletrônicas que tratam da questão da legibilidade não foram transcritos para o quadro 2. 


\section{Quadro 1 - Roteiro A de leitura das páginas eletrônicas - atributos do e-Gov e LAI}

\begin{tabular}{|c|c|c|c|c|c|c|c|c|}
\hline \multicolumn{2}{|c|}{ Indicador } & Finalidade & Atributos & Descrição dos atributos & PB & BA & sc & RS \\
\hline \multirow{16}{*}{ 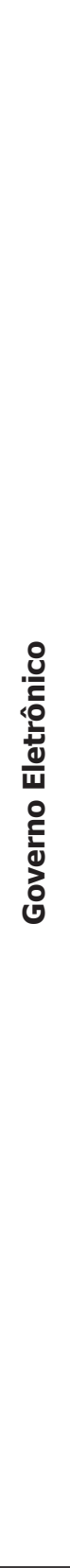 } & \multirow{6}{*}{$\begin{array}{l}\frac{0}{0} \\
\frac{\pi}{0} \\
\frac{0}{0} \\
\frac{0}{0} \\
\frac{0}{0} \\
\frac{\pi}{2} \\
2\end{array}$} & \multirow{6}{*}{$\begin{array}{l}\text { Apontam a } \\
\text { dificuldade } \\
\text { ou facilidade } \\
\text { do usuário } \\
\text { para localizar } \\
\text { a informação } \\
\text { (percurso } \\
\text { percorrido) }\end{array}$} & $\begin{array}{l}\text { Presença do mapa } \\
\text { do site }\end{array}$ & $\begin{array}{l}\text { Visualização geral da } \\
\text { estrutura da página }\end{array}$ & 1 & 1 & 0 & 1 \\
\hline & & & Campo de busca & $\begin{array}{l}\text { Pesquisa por palavras ou } \\
\text { termos chave }\end{array}$ & 1 & 1 & 1 & 1 \\
\hline & & & $\begin{array}{l}\text { Presença de barra de } \\
\text { estado (migalha de } \\
\text { pão) }\end{array}$ & $\begin{array}{l}\text { Identifica o caminho } \\
\text { percorrido até a página } \\
\text { atual }\end{array}$ & 1 & 1 & 1 & 1 \\
\hline & & & $\begin{array}{l}\text { Acesso à info. de } \\
\text { forma fácil e intuitiva }\end{array}$ & $\begin{array}{l}\text { Forma de localizar a } \\
\text { informação }\end{array}$ & 1 & 1 & 1 & 1 \\
\hline & & & $\begin{array}{l}\text { Acesso à info. em } \\
\text { até } 3 \text { cliques da pág. } \\
\text { principal }\end{array}$ & $\begin{array}{l}\text { Forma de localizar a } \\
\text { informação }\end{array}$ & 1 & 1 & 1 & 1 \\
\hline & & & $\begin{array}{l}\text { Formas diferenciadas } \\
\text { de seleção do serviço }\end{array}$ & $\begin{array}{l}\text { Acesso diferenciado por } \\
\text { perfil de usuário ou áreas } \\
\text { de interesse. }\end{array}$ & 0 & 1 & 1 & 1 \\
\hline & \multirow{3}{*}{ 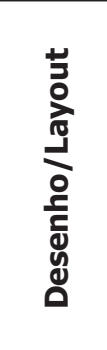 } & \multirow{3}{*}{$\begin{array}{l}\text { Importantes na } \\
\text { percepção da } \\
\text { informação }\end{array}$} & $\begin{array}{l}\text { Uniformidade/padrão } \\
\text { de apresentação e } \\
\text { formatos }\end{array}$ & $\begin{array}{l}\text { Padronização de ícones, } \\
\text { cores, logotipo e } \\
\text { elementos comuns }\end{array}$ & 1 & 1 & 1 & 1 \\
\hline & & & Fundos neutros & $\begin{array}{l}\text { Fundo não sobressair à } \\
\text { informação }\end{array}$ & 1 & 1 & 1 & 1 \\
\hline & & & $\begin{array}{l}\text { Alinhamento do texto } \\
\text { à esquerda }\end{array}$ & Mais fácil de ser lido & 1 & 1 & 1 & 1 \\
\hline & \multirow{4}{*}{ 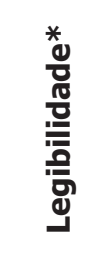 } & \multirow{4}{*}{$\begin{array}{l}\text { Nível de clareza } \\
\text { e compreensão } \\
\text { dos textos por } \\
\text { escolaridade }\end{array}$} & Muito fáceis & Índice entre 75 - 100 & 0 & 0 & 0 & 0 \\
\hline & & & Fáceis & Índice entre $50-75$ & 0 & 0 & 0 & 0 \\
\hline & & & Difíceis & Índice entre 25 - 50 & 0 & 1 & 0 & 0 \\
\hline & & & Muitos difíceis & Índice entre $0-25$ & 1 & 0 & 1 & 1 \\
\hline & \multirow{3}{*}{ 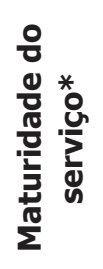 } & \multirow{3}{*}{$\begin{array}{l}\text { Oferta de } \\
\text { serviços } \\
\text { eletronicamente }\end{array}$} & Informação & Apenas informações & 1 & 0 & 0 & 0 \\
\hline & & & Interação & $\begin{array}{l}\text { Pesquisas ou emissão de } \\
\text { formulários }\end{array}$ & 0 & 1 & 1 & 1 \\
\hline & & & Transação & $\begin{array}{l}\text { Obtenção completa do } \\
\text { serviço on-line } 24 \mathrm{~h}\end{array}$ & 0 & 0 & 0 & 0 \\
\hline \multirow{4}{*}{ 妾 } & \multirow{4}{*}{ 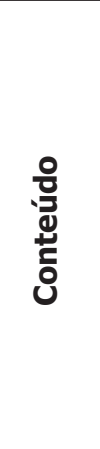 } & \multirow{4}{*}{$\begin{array}{l}\text { Assegurar } \\
\text { o direito } \\
\text { fundamental } \\
\text { de acesso à } \\
\text { informação }\end{array}$} & $\begin{array}{l}\text { Endereço, telefone } \\
\text { e horários de } \\
\text { atendimento }\end{array}$ & $\begin{array}{l}\text { Indentificação do local } \\
\text { onde se deve buscar o } \\
\text { serviço presencialmente }\end{array}$ & 0 & 1 & 1 & 1 \\
\hline & & & $\begin{array}{l}\text { Respostas/perguntas } \\
\text { frequentes (FAQ) }\end{array}$ & $\begin{array}{l}\text { Comunicação direta/ } \\
\text { dúvidas mais comuns }\end{array}$ & 0 & 1 & 0 & 1 \\
\hline & & & $\begin{array}{l}\text { Identificação das } \\
\text { fontes de informação }\end{array}$ & $\begin{array}{l}\text { Segurança da info./ } \\
\text { confiabilidade }\end{array}$ & 0 & 0 & 0 & 0 \\
\hline & & & $\begin{array}{l}\text { Data da última } \\
\text { atualização }\end{array}$ & Informações atualizadas & 0 & 0 & 1 & 0 \\
\hline
\end{tabular}

Fonte: Elaborado pelos autores (2020).

*Os indicadores de Governo Eletrônico (e-Gov) "Legibilidade" e "Maturidade" do serviço são de ordem qualitativa, não sendo quantificáveis numericamente na verificação dos atributos. 
Quadro 2 - Índice de legibilidade segundo Roteiro A

\begin{tabular}{|c|c|c|c|c|c|c|c|}
\hline SES & Texto & $\begin{array}{l}\text { Localização do } \\
\text { texto }\end{array}$ & $\begin{array}{l}\text { Média } \\
\text { palavras/ } \\
\text { sentença }\end{array}$ & $\begin{array}{l}\text { Média } \\
\text { sílabas/ } \\
\text { palavra }\end{array}$ & Índice & $\begin{array}{l}\text { Facilidade } \\
\text { de leitura }\end{array}$ & $\begin{array}{l}\text { Grau de } \\
\text { escolaridade }\end{array}$ \\
\hline RS & $\begin{array}{l}\text { Componente } \\
\text { Especializ. }\end{array}$ & $\begin{array}{l}\text { Inicial > Saúde } \\
\text { e Você > } \\
\text { Medicamentos > } \\
\text { CEAF }\end{array}$ & 7,14 & 2,71 & 12,32 & $\begin{array}{l}\text { Muitos } \\
\text { difíceis } \\
(0-25)\end{array}$ & $\begin{array}{l}\text { Áreas } \\
\text { acadêmicas } \\
\text { específicas }\end{array}$ \\
\hline PPB & $\begin{array}{l}\text { Assistência } \\
\text { Farmac. no } \\
\text { SUS }\end{array}$ & $\begin{array}{l}\text { Inicial > AF no } \\
\text { SUS }\end{array}$ & 14,12 & 2,56 & 17,93 & $\begin{array}{l}\text { Muitos } \\
\text { difíceis } \\
(0-25)\end{array}$ & $\begin{array}{l}\text { Áreas } \\
\text { acadêmicas } \\
\text { específicas }\end{array}$ \\
\hline SSC & $\begin{array}{l}\text { Solicitar } \\
\text { medicam. do } \\
\text { CEAF }\end{array}$ & $\begin{array}{l}\text { Portal de } \\
\text { serviços } \\
\text { > solicitar } \\
\text { medicamentos } \\
\text { do CEAF }\end{array}$ & 9,26 & 2,69 & 11,86 & $\begin{array}{l}\text { Muitos } \\
\text { difíceis } \\
(0-25)\end{array}$ & $\begin{array}{l}\text { Áreas } \\
\text { acadêmicas } \\
\text { específicas }\end{array}$ \\
\hline BBA & $\begin{array}{l}\text { Medicam. } \\
\text { Especializ. }\end{array}$ & $\begin{array}{l}\text { Início > Atenção } \\
\text { à saúde > } \\
\text { Atendimento ao } \\
\text { cidadão > AF } \\
\text { > Medicamentos } \\
\text { Especializados }\end{array}$ & 7,39 & 2,54 & 26,45 & $\begin{array}{l}\text { Difíceis } \\
(25-50)\end{array}$ & $\begin{array}{l}\text { Ensino } \\
\text { médio ou } \\
\text { universitário }\end{array}$ \\
\hline
\end{tabular}

Fonte: Elaborado pelos autores (2020). 
Quadro 3 - Roteiro B de leitura das páginas eletrônicas - atributos do CEAF

\begin{tabular}{|c|c|c|c|c|c|c|c|}
\hline Fonte & $\begin{array}{c}\text { Etapa } \\
\text { Execução }\end{array}$ & Finalidade & Atributos & $\begin{array}{l}\text { SES } \\
\text { PB }\end{array}$ & $\begin{array}{c}\text { SES } \\
\text { BA }\end{array}$ & SES & $\begin{array}{l}\text { SES } \\
\text { RS }\end{array}$ \\
\hline \multirow{14}{*}{ 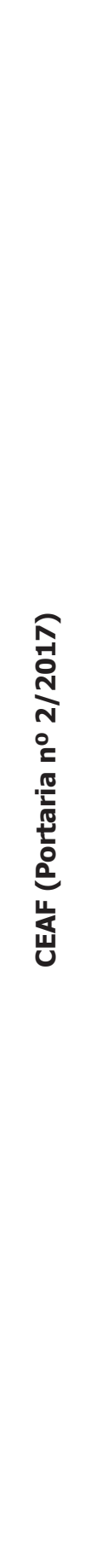 } & \multirow{2}{*}{ Geral } & \multirow{2}{*}{$\begin{array}{l}\text { Dispor de informações } \\
\text { gerais da política } \\
\text { nacional de } \\
\text { medicamentos - AF }\end{array}$} & $\begin{array}{l}\text { Informações gerais sobre a política de } \\
\text { AF (organização por componentes) }\end{array}$ & 0 & 1 & 1 & 1 \\
\hline & & & $\begin{array}{l}\text { Informação que permita identificar } \\
\text { o Componente ao qual pertence o } \\
\text { medicamento }\end{array}$ & 0 & 1 & 1 & 1 \\
\hline & \multirow{9}{*}{ Solicitação } & \multirow{9}{*}{$\begin{array}{l}\text { Dispor de informações } \\
\text { para a solicitação inicial } \\
\text { do cadastro no CEAF }\end{array}$} & $\begin{array}{l}\text { Relação dos locais de cadastro } \\
\text { (endereço) }\end{array}$ & 0 & 1 & 1 & 1 \\
\hline & & & Contato para o CEAF (telefone ou e-mail) & 0 & 1 & 1 & 1 \\
\hline & & & $\begin{array}{l}\text { Relação de documentos necessários para } \\
\text { o cadastro }\end{array}$ & 0 & 1 & 1 & 1 \\
\hline & & & $\begin{array}{l}\text { Prazos de validade dos documentos para } \\
\text { cadastro e período de renovação }\end{array}$ & 0 & 0 & 1 & 0 \\
\hline & & & $\begin{array}{l}\text { Lista de doenças contempladas no CEAF } \\
\text { do estado }\end{array}$ & 0 & 1 & 1 & 0 \\
\hline & & & $\begin{array}{l}\text { Lista de medicamentos do CEAF do } \\
\text { estado }\end{array}$ & 1 & 1 & 1 & 1 \\
\hline & & & PCDTs ou link para os mesmos & 0 & 1 & 1 & 1 \\
\hline & & & $\begin{array}{l}\text { Formulário (LME) para download ou } \\
\text { impressão/preenchimento }\end{array}$ & 0 & 1 & 1 & 1 \\
\hline & & & Orientações para preenchimento do LME & 0 & 0 & 0 & 0 \\
\hline & Avaliação & $\begin{array}{l}\text { Etapa de verificação } \\
\text { do cumprimento de } \\
\text { critérios para inclusão } \\
\text { no CEAF }\end{array}$ & $\begin{array}{l}\text { Informações sobre o fluxo de avaliação } \\
\text { (como é feito, tempo de análise) }\end{array}$ & 0 & 1 & 1 & 0 \\
\hline & Dispensação & $\begin{array}{l}\text { Etapa de entrega dos } \\
\text { medicamentos para o } \\
\text { usuário/responsável } \\
\text { legal }\end{array}$ & $\begin{array}{l}\text { Informações sobre as dispensações } \\
\text { (periodicidade, documentos, interrupção, } \\
\text { quem pode retirar) }\end{array}$ & 0 & 1 & 1 & 1 \\
\hline & Renovação & $\begin{array}{l}\text { Etapa necessária } \\
\text { para continuidade do } \\
\text { tratamento realizado } \\
\text { trimestralmente }\end{array}$ & $\begin{array}{l}\text { Informações sobre as renovações do } \\
\text { cadastro (periodicidade, documentos, } \\
\text { prazos) }\end{array}$ & 0 & 1 & 1 & 1 \\
\hline
\end{tabular}

Fonte: Elaborado pelos autores (2020).

A análise dos sites das duas SES da região Nordeste começará, em seguida, pelo estado que tem o melhor indicador de acesso ao CEAF, a Paraíba (SES/PB).

A página eletrônica de abertura da SES/PB, ou página inicial, apresenta elevado nível de carga informacional, i.e., excesso de links e banners de conteúdo e banner específico denominado 'Saúde' (uma lista de serviços por assuntos diversos, aparentemente sem critério de ordenação, dentre os quais o link 'Assistência 
Farmacêutica'). No conteúdo destinado ao cidadão (banner 'Cidadão') não foi identificado nenhum serviço relacionado à saúde. No banner 'Serviços', encontra-se o link 'Saúde - Lista de medicamentos'; contudo, em diversas tentativas realizadas, nenhuma página foi aberta a partir deste link. Ou seja, o acesso ao conteúdo da AF só é possível unicamente pelo link 'Assistência Farmacêutica', que mantém o padrão da página inicial dada a existência de uniformidade de apresentação (formatos com padronização de ícones: identidade visual do sítio e a padronização das páginas, posicionamento dos elementos na tela, cores, logotipo e elementos comuns), mas, com redução da carga informacional. Não obstante, a mistura de formato das fontes do texto com alternância entre caixa baixa e alta contribui negativamente para a organização visual da página.

A página da $\mathrm{AF}$ atende a oito dos nove atributos de e-Gov (ver Roteiro A, quadro 1), não apresentando formas diferenciadas de seleção do serviço, uma vez que o conteúdo está disponível unicamente em 'Saúde' > 'Assistência Farmacêutica'. No teste realizado para verificação da funcionalidade da ferramenta 'campo de busca', esta se mostrouefetiva no retorno à pesquisa realizada. O aspecto 'identidade visual' (layout, quadro 1) atende a todos os atributos por apresentar uniformidade/padrão de apresentação e formatos, contraste positivo entre informação e fundo da tela (fundo neutro) e alinhamento do texto à esquerda. Contudo, nenhum dos quatro atributos da LAI foi atendido, a saber: presença de endereços e telefones das respectivas unidades e horários de atendimento ao público, data da última atualização da informação, FAQ (respostas às perguntas mais frequentes) e identificação das fontes de informação.

Em relação à maturidade do serviço público em formato eletrônico, a página da SES/PB pode ser categorizada como baixa no nível de informação, uma vez que não permite interface entre a página e o usuário. Quanto à clareza e linguagem adotadas, o único texto disponível, analisado foi 'Assistência Farmacêutica' no SUS, que apresentou predominância de linguagem técnica. Na construção do índice de legibilidade, o texto foi classificado como 'muito difícil', i.e., textos adequados para áreas acadêmicas específicas (índice entre zero e 25) (ver quadro 2).

Embora o site da SES/PB apresente na página inicial o link permanente para 'Assistência Farmacêutica', há disponibilização insuficiente de informações sobre o CEAF: em relação aos 14 atributos, apenas a lista de medicamentos foi identificada (ver roteiro B, quadro 3).

A página eletrônica de abertura da SES/BA apresenta elementos de usabilidade e de layout que, de forma geral, a caracterizam como uma página limpa e organizada: nível adequado de carga informacional, espaços em branco, presença de fundo neutro, contraste de cores do texto e alinhamento do texto à esquerda. As informações estão organizadas por banners de conteúdo (Início, Acesso rápido, Institucional, Atenção à saúde, Educação, Vigilância em saúde, Eventos, Notícias, Мenu de governo), perfil de usuário/público alvo (Atendimento ao Cidadão, Serviços Móveis, Municípios e regionalização, e Fornecedores) e alguns banners temáticos ('Acesso a medicamentos', ouvidoria, etc.).

Além do link permanente já citado, 'Acesso a medicamentos', o acesso à página de medicamentos ocorre também pelo banner 'Acesso rápido', 'Atenção à saúde' e 'Atendimento ao Cidadão', ou seja, a navegação para o acesso às informações sobre a $\mathrm{AF}$, que mantém o mesmo padrão da página inicial, é possível por diversos caminhos que direcionam para uma mesma página. Além disso, o site apresenta o link permanente para 'Acesso a medicamentos' na página de abertura facilitando a identificação do conteúdo logo no primeiro acesso.

Em síntese, a página da $\mathrm{AF}$ atende a todos os nove atributos de e-Gov e a dois dos quatro atributos da LAI, exceto a identificação das fontes de informação e data da última atualização (esta foi encontrada apenas no guia de orientação ao usuário). No teste realizado para verificação da funcionalidade da ferramenta 'campo de busca', ela se mostrou efetiva no retorno à pesquisa realizada. Pela possibilidade de se baixar arquivos (download) por meio da página eletrônica, a página se enquadra no nível de maturidade de interação, uma vez que possibilita algumas interfaces com o cidadão (ver Roteiro A, quadro 1). Quanto aos 14 atributos do CEAF (ver Roteiro B, quadro 3), o site atende a 12 deles, mas não tem prazos de validade 
dos documentos especificados para o cadastro e período de renovação, além da falta de Informações sobre o fluxo de avaliação (como é feito, tempo de análise). Apesar disso, a página da AF reúne diversos elementos positivos voltados para o acesso aos serviços da AF como um todo e, especificamente, os relativos ao CEAF.

Na leitura direta do texto da página eletrônica da Bahia (Assistência Farmacêutica > Medicamentos Especializados), identificamos a predominância de termos técnicos, o que concorre para que o índice de legibilidade enquadre o texto como de difícil compreensão, ou seja, um texto adequado a alunos cursando o ensino médio ou universitário (ver quadro 2).

Analisaremos a seguir a realidade de dois dos três estados da região Sul do país, começando pelo estado de Santa Catarina. A página inicial da SES/SC apresenta elementos de usabilidade e de layout que a caracterizam, de forma geral, como uma página limpa e organizada, por não concentrar um grande volume de informações, possuir espaços em branco, fundo neutro, contraste positivo de cores do texto, alinhamento do texto à esquerda; tudo conforme o padrão do layout estabelecido voltado para o uso adequado pelo cidadão.

Na página inicial podemos identificar as informações organizadas por banners de conteúdo (Serviços, A Secretaria, Gabinete Do Secretário, Legislação, Contato), por perfil de usuário/público alvo em 'Serviços disponíveis' (Serviços para o cidadão, Notícias, Gestores da saúde, Profissionais de saúde, Servidores da SES e Prestadores de serviços) e, no rodapé da página, o banner do 'Portal de serviços do Poder Executivo de Santa Catarina'.

Dentre os perfis de usuários listados, o conteúdo para a política de medicamentos foi localizado apenas no perfil do profissional de saúde. Outro caminho possível é por meio do 'Portal de serviços do Poder Executivo de Santa Catarina'. Já nos demais banners de conteúdo e perfis de usuário, inclusive nos serviços destinados para o cidadão, não foi possível identificar assuntos relacionados à AF. O acesso aos serviços de AF pelo banner 'Portal de Serviços do Poder Executivo de Santa Catarina' se dá por meio do campo de busca do serviço, no qual identificamos o conteúdo (link) 'Solicitar medicamentos do CEAF'. A partir desse link é possível acessar diversas informações sobre o componente especializado numa extensa página única, disponibilizando ainda um novo link da página do serviço (URL do Site). O conteúdo desse é o mesmo do link CEAF do perfil 'Profissionais de saúde' apresentado. Ou seja, as páginas analisadas são comuns ao serviço para profissionais e para o cidadão a partir do 'Portal de Serviços do Executivo'. A página da AF mantém o padrão da página inicial apresentando um esquema de cores condizente com o objetivo do portal e links de hipertexto com decoração e cores consistentes de forma integrada com todo o sítio.

A página da SES/SC atende a oito dos nove atributos de e-Gov, com a ausência do mapa do site, e a dois dos quatro atributos da LAI, exceto FAQ e a identificação das fontes de informação (ver Roteiro A, quadro 1). No teste realizado para verificação da funcionalidade da ferramenta 'campo de busca', a mesma mostrou-se efetiva. É possível fazer download de diversos formulários. Assim, a página se enquadra no nível de maturidade 'interação' ao permitir algumas interfaces entre o cidadão e o serviço de forma eletrônica. Dada a existência do banner do portal de serviços, a busca ocorre de forma fácil, porém, para torná-la mais intuitiva para a população, o mesmo conteúdo deveria estar disponibilizado na área específica para o cidadão. A página da $\mathrm{AF}$ atende a 13 dos 14 atributos do $\mathrm{CEAF}$, exceto o das orientações para o preenchimento do LME (ver Roteiro B, quadro 3). Se, por um lado, o cidadão obtém um rol expressivo de informações para iniciar seu cadastro e seguir nas demais etapas do CEAF estadual, por outro lado, a leitura do texto com as informações no 'Portal de serviços' > 'Solicitar medicamentos do CEAF' aponta para a predominância de termos técnicos, dificultando a compreensão das informações por parte dos cidadãos, com uma classificação do ILT de 'muito difícil', ou seja, textos adequados apenas para áreas acadêmicas específicas (ver quadro 2).

Finalmente, em relação ao Rio Grande do Sul, a página inicial da SES/RS apresenta como característica elementos de usabilidade, layout limpo e organizado, presença de fundo neutro, contraste positivo de cores do texto, alinhamento do texto à esquerda, conforme os padrões de layout estabelecidos para uma adequada usabilidade pelo usuário. As informações encontram-se organizadas por banners de conteúdo (Inicial, 
Institucional, Comunicação, Saúde e você) e por perfil de usuário (Cidadão, Gestor e prestador e, Profissional de Saúde). No item 'Os mais procurados', há uma descrição dos conteúdos mais acessados. Desse modo, apresenta formas diferenciadas de seleção do serviço da AF, a partir da página inicial, sendo possível acessá-la em 'Os mais procurados', 'Saúde e você’ e ‘Cidadão' > 'Perguntas frequentes'. Um traço singular é que todos os elementos de conteúdo que estruturam o site são direcionados para a página 'Medicamentos', além de 'Os mais procurados' permitir que se encontre o link 'Consulta à solicitação de medicamento ou fórmula nutricional'. Ao clicar no link 'Medicamentos', abre-se uma página com orientações de 'Como ter acesso a medicamentos no SUS' para os Componentes da AF e outros tópicos relacionados. Essa página também mantém o padrão de layout da página eletrônica de abertura.

A página da SES/RS atende a todos os nove atributos de e-Gov e a dois dos quatro atributos da LAI, exceto o da identificação das fontes de informação e da data da última atualização (ver Roteiro A, quadro 1). No teste de verificação da funcionalidade da ferramenta 'campo de busca', esta se mostrou efetiva no retorno à pesquisa realizada. Pela página é possível fazer download de formulários e arquivos, além de realizar consultas sobre a disponibilidade de medicamentos em estoque e a situação do processo de solicitação do medicamento. Essa característica enquadra a página no nível de maturidade de 'interação', porque permite interfaces entre o serviço eletrônico e o cidadão. Por sua vez, são contemplados 10 entre os 14 atributos do CEAF, ou seja, não foram incorporados a lista de doenças, os prazos de validade dos documentos para cadastro e período de renovação, as orientações para preenchimento do LME e as informações sobre o fluxo de avaliação (como é feito, tempo de análise) (ver Roteiro B, quadro 3). Contudo, a página sobre o CEAF é bastante rica em informações abrangendo explicação sobre o que é o CEAF, forma de financiamento, como realizar cadastro e os locais para fazê-lo.

A leitura do texto disponível em 'Saúde e Você’ > 'Medicamentos' > 'Componente Especializado' ressalta a predominância de termos técnicos dificultando a compreensão pela população em geral, com o ILT de 'muito difícil', i.e., texto adequado apenas para áreas acadêmicas específicas (ver quadro 2).

\section{DISCUSSÃO}

Em termos de alocação de recursos públicos (ver tabela 2), as regiões Norte e Nordeste apresentam os piores gastos médios per capita com medicamentos do CEAF, quando comparado às demais regiões do país: região Norte $(\mathrm{R} \$ 62,68)$ apresenta gasto equivalente a $1 / 5$ da região $\operatorname{Sul}(\mathrm{R} \$ 300,30)$, que representa a melhor média das regiões do país.

No caso dos quatro estados aqui analisados, a Bahia se destaca como tendo a pior alocação de recursos médio per capita no CEAF ( $\mathrm{R} \$ 62,03)$, correspondendo a menos da metade do valor gasto pelo Rio Grande do Sul, que é o estado com o menor valor da região Sul (R\$ 142,58). Comparando a melhor alocação de recursos, a Paraíba ( $\mathrm{R} \$ 257,02)$ se destaca com precentual de 68\% quando comparado a Santa Catarina ( $\mathrm{R}$ \$ 373,68), o estado melhor posicionado na região Sul. Conforme os números apresentados na tabela 2, observa-se também discrepância intra-regional, com o estado da Paraíba com locação quatro vezes superior à da Bahia e o estado do Rio Grande do Sul com locação 2,6 vezes superior a Santa Catarina. Esses resultados expressam, portanto, uma desigualdade de acesso aos serviços de saúde (médicos especializados, diagnóstico da doença, prescrição, entre outros) e de medicamentos especializados.

Em relação às características das páginas eletrônicas das SES, não podemos inferir que haja uma relação direta entre o desempenho do CEAF e a qualidade informacional dessas páginas, uma vez que há experiências exitosas entre os estados de ambas as regiões do país aqui analisados, exceto o estado da Paraíba.

Não há entre as páginas das SES um padrão de organização e disponibilização das informações sobre a política do CEAF. Três estados (Bahia, Santa Catarina e Rio Grande do Sul) apresentam as informações de fácil acesso, com a disponibilização de formulários ou outros documentos para download, exibindo, por- 
tanto, nível de maturidade do serviço eletrônico no nível de interação. Nenhum deles atende aos atributos legalmente intituídos a ponto de ser qualificado como o 'nível transação', i.e., dispor de serviço eletrônico inteiramente on-line 24h (ver Roteiro A, quadro 1).

Ainda que diversos itens dos Roteiros A e B tenham sido levados em consideração pelas páginas das SES, a linguagem adotada nos textos destinados aos cidadãos apresenta um forte componente técnico que compromete o entendimento pela população em geral. Todos os textos analisados apresentaram índices de legibilidade variando entre 'difícil' e 'muito difícil'; característica incompatível com o nível educacional dos brasileiros apresentado pelos dados oficiais (tabela 3). Ou seja, em nenhuma das páginas estaduais analisadas há uma composição de linguagem clara e compreensível.

A despeito desse fato, podemos apontar cinco características das três experiências exitosas que poderiam ser observadas por outras iniciativas estaduais no processo de democratização das informações da política de medicamentos especializados para os cidadãos. São elas: a) disponibilizar fluxos de acesso para os medicamentos; b) organizar guias de orientação específica por doença; c) dispor de informações em diferentes formatos e linguagens, utilizando a variedade de recursos disponíveis, tais como, texto, FAQ, vídeo, desenhos, imagens etc.; d) dispor de formulário LME para download ou preenchimento eletrônico para impressão posterior; e) permitir consulta à situação da solicitação do medicamento com os possíveis status (deferido, deferido sem estoque, indeferido ou pendente), à data do último atendimento ou dispensação e ao estoque dos medicamentos.

\section{CONSIDERAÇÕES FINAIS}

Hoje, três décadas após a pobreza e a desigualdade terem sido assumidas como dívidas sociais a serem sanadas, elas continuam, juntamente com a iniquidade, a insistentemente bater em nossas portas, ao mesmo tempo em que percebemos se aprofundar a distância existente entre lei e realidade.

Nesse sentido, os limites e desafios a serem superados pelos agentes políticos na publicização de informações para uma população com baixo nível de escolaridade consistem em dispor de informações seguras, baseadas em fontes confiáveis e comunicadas em linguagem de ampla compreensão pelos usuários do SUS, ao mesmo tempo que possibilite ao cidadão o acompanhamento da política de medicamentos especializados e sua permanente atualização. Para tanto, é preciso que os gestores, técnicos e profissionais responsáveis pela alimentação das páginas eletrônicas conheçam o perfil da população de seus respectivos estados para prover as condições reais para a apropriação cidadã dos serviços prestados pelas Secretarias de Saúde. Finalmente, ainda que não tenha sido objeto desse estudo, é imperativo que seja resolvida a questão da acessibilidade aos usuários portadores de deficiências especiais.

\section{REFERÊNCIAS}

1. Lopes PF, Machado CJS, Teixeira MO. A bula de medicamentos e a regulação de suas configurações em termos de forma e conteúdo no Brasil. Saúde Soc. 2014;(23):277-292.

2. Ministério da Saúde (BR). Componente Especializado da Assistência Farmacêutica: inovação para a garantia do acesso a medicamentos no SUS. Brasília, DF: Ministério da Saúde; 2014.

3. Portaria de Consolidação $n^{0} 2$ (BR), de 28 de setembro de 2017. Consolidação das normas sobre as políticas nacionais de saúde do Sistema Único de Saúde. DOU 2017 out. 03.

4. Gadelha CAG. Desenvolvimento e inovação: a saúde como uma oportunidade. Jornal do Brasil 2019 Jan 31.

5. Lascoumes P, Le Galès P. A ação pública abordada por seus instrumentos. Revista Pós Ciênc Soc. 2012;9(18):19-44.

6. Instituto Brasileiro de Geografia e Estatística (IBGE). Pesquisa Nacional por Amostra de Domicílios: internet 2017. Rio de Janeiro: IBGE; 2017. 
7. Instituto Paulo Montenegro. Indicador de alfabetismo funcional - INAF Brasil 2018. Resultados preliminares. São Paulo: INAF; 2018.

8. Garcia LP, Silva GDM. Doenças Transmissíveis e Situação Socioeconômica no Brasil: Análise Espacial. IPEA 2016:56.

9. $\quad$ Instituto Brasileiro de Geografia e Estatística (IBGE). Síntese de Indicadores sociais: uma análise das condições de vida da população brasileira. Rio de Janeiro: IBGE; 2018.

10. Lei no 12.527 (BR), de 18 de novembro de 2011. Regula o acesso a informações previsto no inciso XXXIII do art. $5^{\circ}$, no inciso II do $\S 3^{\circ}$ do art. 37 e no $\S 2^{\circ}$ do art. 216 da Constituição Federal; altera a Lei no 8.112, de 11 de dezembro de 1990; revoga a Lei no 11.111, de 5 de maio de 2005, e dispositivos da Lei no 8.159, de 8 de janeiro de 1991; e dá outras providências. DOU 2018 nov. 18.Brasil. Padrões Web em Governo Eletrônico: Cartilha de Usabilidade. Brasília: 2010. 50 p.

11. Karnal AR, Pereira VW. O uso de software para medir a complexidade do texto. Hipertextus Revista Digital 2013;(11):1-11.

12. Maria E, Barboza F. A linguagem clara em conteúdos de websites governamentais para promover a acessibilidade a cidadãos com baixo nível de escolaridade. Inclusão Soc. 2010;4(1):52-66.

13. Scarton C, Aluísio SM. Análise da Inteligibilidade de textos via ferramentas de Processamento de Língua Natural: adaptando as métricas do Coh-Metrix para o Português. Linguamática. 2010;(2):45-61.

14. Martins TBF, Ghiraldelo CM, Nunes MGV, Oliveira Junior ON. Readability formulas applied to textbooks in brazilian portuguese. São Carlos: Instituto de Ciências Matemáticas de São Carlos-USP; 1996. 